\title{
Serum Markers of Epithelial Mesenchymal Transition as Predictors of HCV-induced Liver Fibrosis, Cirrhosis and Hepatocellular Carcinoma
}

\author{
Mona M Zoheiry ${ }^{1}$, Shaimaa AA Hasan ${ }^{1}$, Eman El-Ahwany ${ }^{1}$, Faten M Nagy ${ }^{1}$, Hoda Abu Taleb $^{2}$, Mona Nosseir ${ }^{3}$, \\ Mona Magdy ${ }^{3}$, Safa Meshaal ${ }^{5}$, Mohamed Darwish EL-Talkawy ${ }^{4}$, Inas Raafat ${ }^{5}$
}

${ }^{1}$ Department of Immunology, Theodor Bilharz Research Institute, Faculty of Medicine, Cairo University, Giza, Egypt

${ }^{2}$ Environmental Department, Theodor Bilharz Research Institute, Faculty of Medicine, Cairo University, Giza, Egypt

${ }^{3}$ Department of Pathology, Theodor Bilharz Research Institute, Faculty of Medicine, Cairo University, Giza, Egypt

${ }^{4}$ Department of Gastroenterology, Theodor Bilharz Research Institute, Faculty of Medicine, Cairo University, Giza, Egypt

${ }^{5}$ Department of Clinical Pathology, Faculty of Medicine, Cairo University, Giza, Egypt

Type of article: Original

\begin{abstract}
Introduction: Hepatitis $\mathrm{C}$ virus $(\mathrm{HCV})$ is a major cause of chronic liver disease in Egypt, leading to hepatic fibrosis, liver cirrhosis (LC), and hepatocellular carcinoma (HCC). Liver fibrosis is characterized by excessive deposition of extracellular matrix (ECM). Newly-recognized pathogenic mechanisms point to the epithelialmesenchymal transition (EMT) of hepatocytes to matrix synthesizing (myo-) fibroblasts. Transforming growth factor-beta (TGF- $\beta 1$ ), bone morphogenic protein (BMP)-7, and connective tissue growth factor (CTGF) are biomarkers reflecting the EMT process. YKL-40 is a glycoprotein member of ECM and plays a role in cancer cell proliferation. The purpose of this study was to determine the serum biomarkers of EMT and its impact on the fibrogenic process and tumorigenesis in $\mathrm{HCV}$-genotype 4 patients.

Methods: In this case-control study that was conducted in 2013-2014, 97 HCV-infected patients were subjected to clinical examination, laboratory investigations, and liver biopsy. According to the histopathologic examination, they were classified to F0 (14 cases), F1 (17 cases), F2 (15 cases), F3 (18 cases), F4 (22 cases), and HCC (11 cases). Fifteen age- and gender-matched subjects were included as normal controls. Serum levels of TGF- $\beta 1$, BMP-7, CTGF, YKL-40 were assessed, and the TGF- $\beta 1 /$ BMP-7 ratios were calculated. The data were analyzed by plotting the receiver operating characteristic curve (ROC), Pearson product-moment correlation coefficient, and Spearman's rank correlation coefficient (Spearman's rho).

Results: Serum levels of TGF- $\beta 1$, BMP-7, CTGF, and YKL-40 were significantly increased in all patient groups compared to controls $(\mathrm{p}<0.001)$. LC exhibited the highest CTGF level and YKL-40 was highest in HCC. The TGF- $\beta 1 /$ BMP-7 ratios reflected the progression of EMT from CHC to LC, however, there was no significant difference between LC and HCC. TGF- $\beta 1 /$ BMP-7 ratio is considered to reflect positive correlation with CTGF in LC group $(\mathrm{r}=0.629 ; \mathrm{p}<0.03)$ and YKL-40 in HCC group $(\mathrm{r}=0.504 ; \mathrm{p}<0.04)$.

Conclusion: Increased TGF- $\beta 1 /$ BMP-7 ratio and CTGF levels reflect the rate of EMT and provide information about fibrogenic activity. Also, this ratio, in association with YKL-40, can be used to predict malignant transformation in $\mathrm{HCV}$-genotype 4 Egyptian patients.

Keywords: Liver Fibrosis, Transforming Growth Factor-Beta (TGF- $\beta$ ), Bone Morphogenic Protein (BMP)-7, Connective Tissue Growth Factor (CTGF), YKL-40
\end{abstract}

\section{Corresponding author:}

Professor Dr. Mona MM Zoheiry, Theodor Bilharz Research Institute, Warak El-Hadar, Imbaba, P.O. Box 30 Imbaba, 12411 Giza, Egypt, Tel: +20.01115387880, E-mail: mzoheiry@yahoo.com

Received: August 04, 2015, Accepted: September 13, 2015, Published: December 2015

iThenticate screening: September 18, 2015, English editing: October 10, 2015, Quality control: November 08, 2015 (C) 2015 The Authors. This is an open access article under the terms of the Creative Commons Attribution-NonCommercialNoDerivs License, which permits use and distribution in any medium, provided the original work is properly cited, the use is non-commercial and no modifications or adaptations are made. 


\section{Introduction}

Egypt has the highest prevalence of hepatitis C virus (HCV) in the world, estimated nationally at $14.7 \%$ (1) with genotype 4 being the most common (2). HCV infection is a major cause of chronic liver disease, with about 170 million people infected worldwide (3). Patients who have HCV-related cirrhosis have a 2-6\% risk per year of developing HCC (4). Liver fibrosis is characterized by excessive deposition of extracellular matrix (ECM), which is produced by activated myofibroblasts. Liver fibrosis involves molecular and histological re-arrangement of various types of collagens, proteoglycans, and structural glycoproteins (5). Increased matrix production is the most direct way by which hepatic fibrosis is generated (6). YKL-40 ("chondrex", $40 \mathrm{kDa}$ ) is one of glycoprotein members of ECM. It also is a growth factor for fibroblasts and endothelial cells and is strongly expressed in human liver tissue (7), particularly in hepatic stellate cells (HSCs) (8). YKL-40 is believed to be involved in inflammation and remodeling of the ECM through growth factor activity (9). The molecular pathogenesis of liver fibrosis contributes to activation of resting vitamin A-storing HSC, accounting for 5-8\% of total cells in a normal liver, to matrixproducing myo-fibroblasts (MFs) with enhanced secretion of ECM and matrix deposition (10, 11). Newlyrecognized pathogenetic mechanisms of liver fibrosis point to epithelial-mesenchymal transition (EMT) of hepatocytes and bile duct epithelial cells to fibroblasts. These complementary mechanisms enlarge the pool of matrix-synthesizing MFs (8). Among the molecular fibrogenic mediators, transforming growth factor-beta (TGF- $\beta$ ) plays a central role in hepatic fibrogenesis (5). Also, BMP-7 is essential for the regulation of cell proliferation, differentiation, apoptosis and secretion of ECM components. It is thought to have a further inhibitory effect through counteracting TGF- $\beta$ induced fibrosis (12). Similarly, the modulator protein connective tissue growth factor (CTGF/CCN2), which is expressed in hepatocytes, HSC, portal fibroblasts, and cholangiocytes (13, 14), also changes the functional TGF- $\beta$ /BMP-7 ratio (15). This study aimed to analyze the impact of serum biomarkers of EMT on fibrogenic process and progression to tumorogenesis caused by HCV genotype 4 . This can provide insight into the intracellular events relevant to complications associated with $\mathrm{HCV}$ infection.

\section{Material and Methods}

\subsection{Study Design and Patients}

This case-control study involved 97 patients admitted at Hepato-Gastroenterology Department, Theodor Bilharz Research Institute (TBRI), Giza, Egypt for evaluation of their HCV-related chronic liver disease in the period from January 1, 2013, to November 30, 2014. All were HCV genotype 4 positive, with no serologic evidence of coinfection with hepatitis B virus. Patients with chronic viral diseases other than HCV, non-alcoholic steato-hepatitis, autoimmune hepatitis, biliary disorders, and malignancies other than HCC were excluded from the study. All patients gave informed consent prior to inclusion in the study in conformance with the guidelines of the 1975 Declaration of Helsinki as reflected by approval of the institution's human research ethics committee. All procedures were medically indicated for patient management. Clinically and biochemically healthy, roughly age- and gendermatched persons $(n=15)$ served as control subjects. The patients were subjected to thorough clinical examination and were assessed by laboratory investigations, including ultra-sonography and liver biopsy using an ultrasoundguided Menghini needle.

\subsection{Histopathology}

Assessment of grade of inflammation and stage of fibrosis was carried out in 5- $\mu \mathrm{m}$ thick serial sections of formalinfixed, paraffin-embedded blocks, stained with hematoxylin/eosin and Masson trichrome stains. The stage of hepatic fibrosis was determined according to the Metavir scoring system (16). Accordingly, the cases were divided into 64 cases of chronic hepatitis $\mathrm{C}$ (CHC) without cirrhosis including F0 (14 cases), F1 (17 cases), F2 (15 cases) and F3 (18 cases); 22 cases of $\mathrm{CHC}$ with cirrhosis (F4) and 11 cases of $\mathrm{HCV}$-induced well differentiated hepatocellular carcinoma $\mathrm{HCC}(\mathrm{HCC} / \mathrm{HCV})$ (Figure 1).

\subsection{Laboratory Investigations}

\subsubsection{General investigation}

Liver function tests were conducted using commercially-available kits. Hepatitis B markers were tested using enzyme immunoassay kits (Axiom Diagnostics, Burstadt, Germany). CHC was confirmed by HCV infection persisting for longer than six months (HCV-RNA positive) and increased ALT values. Circulating anti-HCV (genotype 4) antibodies were detected using Axiom enzyme immunoassay kit (Axiom Diagnostics, Burstadt, Germany), and the presence of HCV-RNA in patients' sera was detected by real-time polymerase chain using the Amplicor test (Roche Diagnostic Systems; Meylan, France). Serum alpha-FP was tested using the Eurogenetics enzyme immunoassay kit (Tessenderlo, Belgium). 

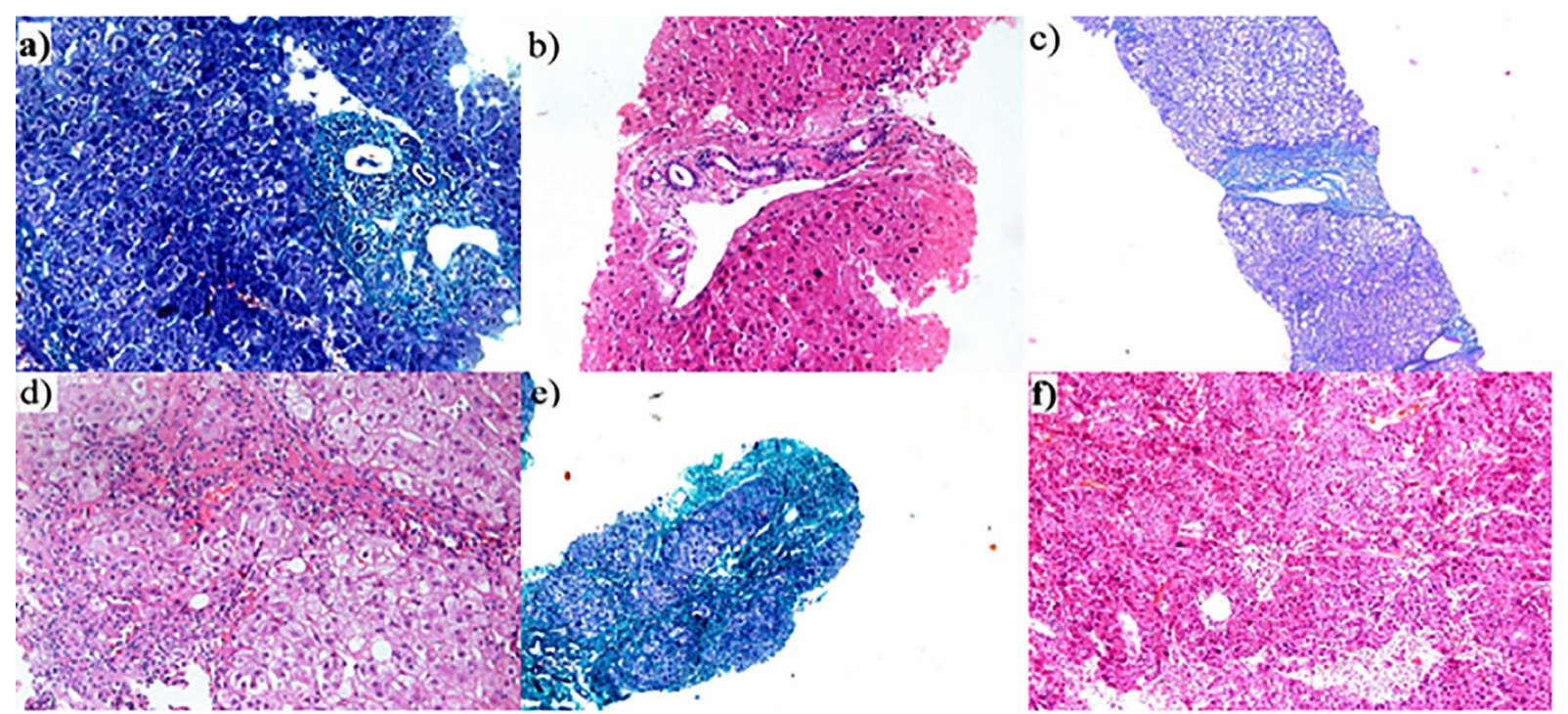

Figure 1. HCV-induced hepatic fibrosis: a) F0 (masson trichrome x 200), b) F1 (H\&E x200), c) F2 (masson x40). d) F3 (H\&Ex200), e) Cirrhosis (F4) (masson trichrome x100), and f) hepatocellular carcinoma (H\&Ex100)

\subsubsection{Serum TGF- $\beta 1$ levels}

Serum TGF- $\beta 1$ levels were assayed using a solid phase enzyme-linked immunosorbent assay kit (DRG International, Inc., USA, Cat. No, EIA-1864) based on the sandwich principle, according to the manufacturer's instructions. The reaction was stopped and the absorbance (OD) of each well was determined using a microtiter plate reader (BioRad) set to $450 \mathrm{~nm}$. The concentration of TGF- $\beta 1$ in the serum samples was determined from the standard curve. All assays were done in duplicate, and the mean concentration was calculated.

\subsubsection{Serum BMP-7 levels}

Serum BMP-7 levels were assayed using a solid-phase, enzyme-linked immunosorbent assay kit Quantikine ELISA kit (Quantikine ${ }^{\circledR}$ ELISA, R\&D Systems, Inc., Minneapolis, USA, Cat. No, DBP700) based on the sandwich principle, according to the manufacturer's instructions.

\subsubsection{Serum CTGF levels}

Serum CTGF levels were assayed using a solid phase enzyme-linked immunosorbent assay kit (DRG International, Inc., USA, Cat. No, EIA-5195), based on the sandwich principle, according to the manufacturer's instructions.

2.3.5. Serum YKL40 levels

Serum YKL40 levels were assayed using a solid-phase, enzyme-linked immunosorbent ELISA kit (AdipoBiotech., Santa Clara, CA, USA, Cat. No, SK00088-02), based on the sandwich principle, according to the manufacturer's instructions.

\subsection{Statistical Analysis}

Analysis of the data was conducted with Microsoft Excel 2007 and SPSS 22 statistical software (SPSS, Inc., Chicago, IL, USA). The data were expressed as the mean \pm SEM. A "p" value of $\leqslant 0.05$ was considered to be statistically significant. The SNK test was used to analyze the difference between two groups. The receiver's operating characteristic curve (ROC) was plotted to assess the diagnostic accuracy of patients with severe liver fibrosis compared to healthy individuals. It was also used to distinguish between patients with severe liver fibrosis and those with mild liver fibrosis. The relationship of the true positivity (sensitivity) and the false positivity (1specificity) was plotted at various cut-off points of the tests. An ideal test was considered to have an AUC of 1.0, with 0.5 indicating no diagnostic value. The interdependence of variables describing relevance was examined by means of the Pearson correlation coefficient (r) and Spearman's rank correlation coefficient (Spearman's rho).

\section{Results}

The biochemical parameters, i.e., AST, ALT, albumin, alkaline phosphatase, PT concentration, and alphafetoprotein (AFP) were within the reference range for control subjects and significantly elevated for patients with CHC, LC, and HCC (Table 1). Serum levels of TGF- $\beta 1$ were significantly higher in the diseased groups than in the controls $(\mathrm{p}<0.001)$. The highest serum level was detected in cirrhotic patients, and it was statistically significant 
compared to CHC ( $p<0.001)$. The TGF- $\beta 1$ concentration in the HCC group was significantly lower than that of the cirrhotic patients $(p<0.01)$ (Table 2). Serum BMP-7 of all patients was higher than that of controls $(p<0.001)$. The highest level was detected in LC patients compared to CHC cases $(p<0.001)$. BMP-7 level in HCC patients was significantly lower than that of CHC and LC cases $(\mathrm{p}<0.01)$ (Table 2$)$. The TGF- $\beta 1 / \mathrm{BMP}-7$ ratio indicated that all patients had higher ratios than the control subjects. CHC patients had lower ratios, while LC and HCC patients had significantly higher ratios ( $<<0.001$ for both) compared to CHC (Table 2). Serum CTGF levels were significantly higher in all patients than in controls $(\mathrm{p}<0.001)$. The highest CTGF concentration was detected in the serum of cirrhotic patients, which was statistically significant compared to CHC patients $(p<0.001)$ (Table 2). Regarding YKL-40, the serum levels in all patients were higher than in the controls $(p<0.001)$. The mean concentration of serum YKL-40 in cirrhotic patients was significantly higher than those with CHC $(p<0.001)$. HCC cases showed significant increase compared to CHC and LC patients ( $p<0.001$ and $\mathrm{p}<0.05$, respectively) (Table 2 ).

Table 1. Clinical and laboratory data of all studied cases

\begin{tabular}{|c|c|c|c|c|c|}
\hline \multicolumn{2}{|l|}{ Variables } & $\begin{array}{l}\text { Controls } \\
(\mathrm{n}=15)\end{array}$ & $\begin{array}{l}\text { CHC without } \\
\text { cirrhosis }(n=64)\end{array}$ & $\begin{array}{l}\text { CHC with } \\
\text { cirrhosis }(n=22)\end{array}$ & $\begin{array}{l}\text { HCV-induced } \\
\text { HCC }(n=11)\end{array}$ \\
\hline \multicolumn{2}{|l|}{ Age } & $45.0 \pm 7.5$ & $47.4 \pm 9.3$ & $51.3 \pm 5.9$ & $48.9 \pm 7.2$ \\
\hline \multicolumn{2}{|l|}{ Gender (M:F) } & $3: 2$ & $3: 1$ & $6: 5$ & $7: 4$ \\
\hline \multirow{5}{*}{$\begin{array}{l}\text { Clinical } \\
\text { findings: } \\
\mathrm{n}(\%)\end{array}$} & Pallor & $0(0)$ & $2(3.1 \%)$ & $5(22.7 \%)$ & $6(54.5 \%)$ \\
\hline & Jaundice & $0(0)$ & $4(6.3 \%)$ & $6(27.3 \%)$ & $8(72.8 \%)$ \\
\hline & Palmar erythema & $0(0)$ & $0(0)$ & $15(68.2 \%)$ & $9(81.2 \%)$ \\
\hline & Spider nevi & $0(0)$ & $0(0)$ & $13(59.1 \%)$ & $9(81.2 \%)$ \\
\hline & Lower-limb edema & $0(0)$ & $0(0)$ & $16(72.3 \%)$ & $5(45.5 \%)$ \\
\hline \multirow{3}{*}{$\begin{array}{l}\text { Child-Pugh } \\
\text { classification }\end{array}$} & $\mathrm{A}$ & $0(0 \%)$ & $64(100 \%)$ & $5(22.7 \%)$ & $1(9.1 \%)$ \\
\hline & $\mathrm{B}$ & $0(0)$ & $0(0)$ & $6(27.3 \%)$ & $4(36.2 \%)$ \\
\hline & $\mathrm{C}$ & $0(0)$ & $0(0)$ & $11(50.0 \%)$ & $6(54.5 \%)$ \\
\hline \multirow{6}{*}{$\begin{array}{l}\text { Liver } \\
\text { function tests } \\
\text { (mean } \pm \\
\text { SEM) }\end{array}$} & AST (U/L) & $32.6 \pm 4.2$ & $63.2 \pm 29.8$ & $51.8 \pm 4.4$ & $78.1 \pm 16.9$ \\
\hline & ALT (U/L) & $31.1 \pm 5.1$ & $49.1 \pm 18.3$ & $46.5 \pm 5.0$ & $68.2 \pm 12.6$ \\
\hline & Alkaline phosphatase (U/L) & $189 \pm 60$ & $331 \pm 78$ & $348 \pm 68$ & $420 \pm 73$ \\
\hline & Albumin (g/dL) & $4.4 \pm 0.5$ & $3.60 \pm 0.85$ & $3.8 \pm 0.72$ & $3.08 \pm 0.48$ \\
\hline & $\mathrm{PC}$ & $97.6 \pm 3.4$ & $89.6 \pm 5.8$ & $41.5 \pm 11.1$ & $68.4 \pm 3.9$ \\
\hline & Alpha-fetoprotein (IU/mL) & $3.39 \pm 2.9$ & $9.38 \pm 13.4$ & $10.35 \pm 15.7$ & $25.02 \pm 27.6$ \\
\hline
\end{tabular}

Data are expressed as mean \pm standard errors (SE) or number (\%). CHC: chronic hepatitis C, HCC: hepatocellular carcinoma, HCV: hepatitis C virus. Normal range for ALT and AST is up to $40 \mathrm{IU} / \mathrm{L}$. Normal range are: alkaline phosphatase: up to $250 \mathrm{U} / \mathrm{L}$, albumin: $3.5-5 \mathrm{~g} / \mathrm{dl}$, PT concentration: $80-100 \%$, alpha-fetoprotein: $0.1-9.6 \mathrm{IU} / \mathrm{mL}$.

Table 2. Serum levels of TGF- $\beta 1$, BMP7, TGF- $\beta 1 / \mathrm{BMP} 7, \mathrm{CTGF}$ and YKL-40 ratio in all studied groups

\begin{tabular}{|l|l|l|l|l|l|l|}
\hline Group & $\mathrm{n}$ & TGF- $\beta 1(\mathrm{pg} / \mathrm{mL})$ & BMP-7 $(\mathrm{pg} / \mathrm{mL})$ & $\begin{array}{l}\text { TGF- } \beta 1 / \text { BMP7 } \\
\text { ratio }\end{array}$ & CTGF $(\mathrm{ng} / \mathrm{mL})$ & YKL-40 $(\mathrm{pg} / \mathrm{mL})$ \\
\hline Control & 15 & $10.98 \pm 0.68$ & $8.35 \pm 0.45$ & $1.35 \pm 0.09$ & $22.97 \pm 4.70$ & $0.58 \pm 0.19$ \\
\hline CHC & 64 & $21.81 \pm 1.78^{\mathrm{a}}$ & $18.63 \pm 1.43^{\mathrm{a}}$ & $1.39 \pm 0.14$ & $63.67 \pm 1.79^{\mathrm{a}}$ & $1.69 \pm 0.14^{\mathrm{a}}$ \\
\hline LC & 22 & $39.87 \pm 3.90^{\mathrm{a}, \mathrm{b}}$ & $22.33 \pm 2.79^{\mathrm{a}, \mathrm{b}}$ & $1.96 \pm 0.11^{\mathrm{a}, \mathrm{b}}$ & $77.08 \pm 4.02^{\mathrm{a}, \mathrm{b}}$ & $2.52 \pm 0.13^{\mathrm{a}, \mathrm{b}}$ \\
\hline HCC & 11 & $20.81 \pm 1.41^{\mathrm{a}, \mathrm{c}}$ & $11.73 \pm 0.79^{\mathrm{a}, \mathrm{c}, \mathrm{d}}$ & $1.89 \pm 0.23^{\mathrm{b}}$ & $69.46 \pm 10.03^{\mathrm{a}}$ & $3.16 \pm 0.20^{\mathrm{a}, \mathrm{b}, \mathrm{e}}$ \\
\hline
\end{tabular}

Data were expressed as mean \pm SEM, ${ }^{a} p<0.001$ (significant increase than control), ${ }^{b} p<0.001$ (significant increase than CHC), ${ }^{\mathrm{c}} p<0.01$ (significant decrease than LC), ${ }^{\mathrm{d}} p<0.01$ (significant decrease than CHC), ${ }^{\mathrm{e}} p<0.05$ (significant increase relative to $\mathrm{LC}$ ).

TGF- $\beta 1$ and BMP-7 serum levels increased gradually with increased stage of fibrosis. TGF- $\beta 1$ and BMP-7 concentrations were significantly higher in stage F4 fibrosis (LC cases) compared to F0 and F1 (p $<0.001$ and $p<$ 0.01 , respectively) (Table 3 ). TGF- $\beta 1 /$ BMP-7 ratio increased gradually with the increasing stage of fibrosis. The greatest value was found in stage F4 compared to F0, F1, F2, and F3 (p<0.05) (Table 3). Cirrhotic patients (F4) had the highest serum level of CTGF compared to F0 and F2 (p<0.001). F2, F3, and F4 stages showed significant increase in serum concentration of YKL-40 compared to F0 and F1 $(\mathrm{p}<0.001)$ (Table 3). Correlation analysis of the EMT markers with each other in all patient groups revealed high significant positive correlations between TGF- $\beta 1$ 
and BMP-7 $(r=0.860, p=0.000)$, CTGF and TGF- $\beta 1 /$ BMP-7 ratio $(r=0.231, p<0.04)$ and also between YKL-40 and TGF- $\beta 1$ /BMP-7 ratio $(r=0.286, p<0.04)$ (Figures $2 a, 2 b$, and $4 c)$. Correlation analysis in LC group revealed positive correlation between TGF- $\beta 1 /$ BMP-7 ratio and serum levels of CTGF $(r=0.629 ; p<0.03)$. In the HCC group, a positive correlation was detected between TGF- $\beta 1 /$ BMP-7 ratio and serum levels of YKL-40 $(r=0.504 ; p$ $<0.04)$.

Table 3. Relationship between stage of fibrosis and cytokine levels

\begin{tabular}{|c|c|c|c|c|c|c|}
\hline $\begin{array}{l}\text { Fibrosis } \\
\text { stage }\end{array}$ & $\mathrm{n}$ & TGF- $\beta 1(\mathrm{pg} / \mathrm{mL})$ & BMP7 $(\mathrm{pg} / \mathrm{mL})$ & $\begin{array}{l}\text { TGF- } \beta 1 / \text { BMP7 } \\
\text { ratio }\end{array}$ & CTGF (ng/mL) & $\begin{array}{l}\text { YKL-40 } \\
(\mathrm{pg} / \mathrm{mL})\end{array}$ \\
\hline F0 & 14 & $18.88 \pm 2.43$ & $15.15 \pm 1.40$ & $1.35 \pm 0.23$ & $54.71 \pm 1.75$ & $0.75 \pm 0.22$ \\
\hline F1 & 17 & $19.31 \pm 2.11$ & $16.98 \pm 2.12$ & $1.46 \pm 0.39$ & $67.03 \pm 2.22$ & $1.27 \pm 0.06$ \\
\hline $\mathrm{F} 2$ & 15 & $23.05 \pm 2.19$ & $19.10 \pm 3.22$ & $1.38 \pm 0.20$ & $65.88 \pm 2.44$ & $2.31 \pm 0.05^{\mathrm{b}}$ \\
\hline F3 & 18 & $25.99 \pm 6.04$ & $21.32 \pm 2.79$ & $1.38 \pm 0.28$ & $70.81 \pm 2.76$ & $2.42 \pm 0.17^{\mathrm{b}}$ \\
\hline F4 & 22 & $39.87 \pm 3.90^{\mathrm{a}}$ & $22.33 \pm 2.79^{b}$ & $1.89 \pm 0.23^{\mathrm{c}}$ & $77.09 \pm 4.02^{\mathrm{d}}$ & $2.56 \pm 0.13^{\mathrm{b}}$ \\
\hline
\end{tabular}

Data were expressed as mean $\pm \mathrm{SEM} ;{ }^{\mathrm{a}} p<0.001$ (significant increase than F0, F1, F2 and F3); ${ }^{\mathrm{b}} p<0.01$ (significant increase than F0 and F1); ${ }^{\mathrm{c}} p<0.05$ (significant increase than F0, F1, F2 and F3); ${ }^{\mathrm{d}} p<0.001$ (significant increase than F0 and F2).
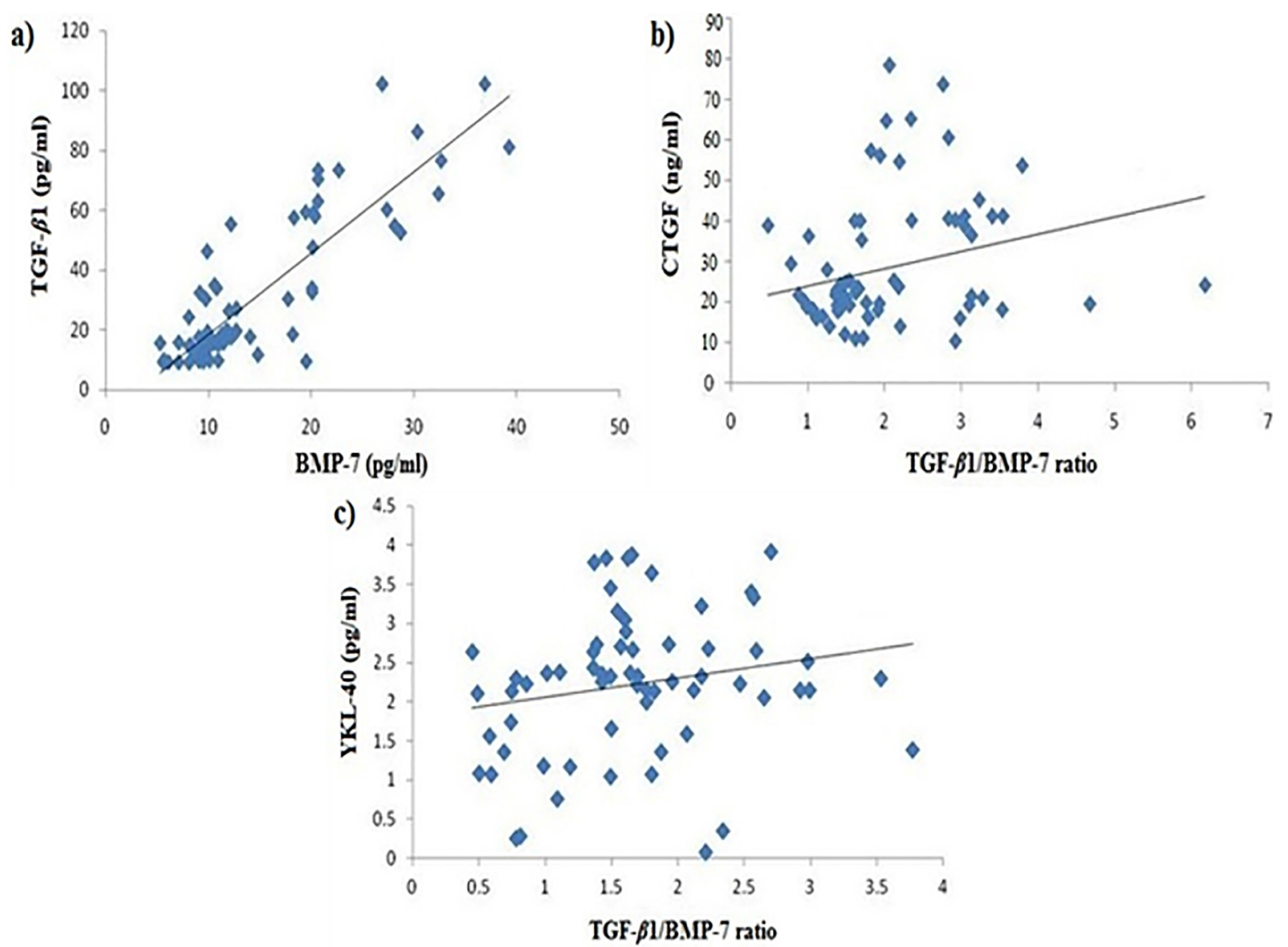

Figure 2. Correlation between: a) TGF- $\beta 1$ and BMP-7 $(r=+0.860, p=0.000)$, b) CTGF and TGF- $\beta 1 / B M P-7$ ratio $(r$ $=+0.231, \mathrm{p}<0.04)$ and $\mathrm{c})$ YKL-40 and TGF- $\beta 1 / \mathrm{BMP}-7$ ratio $(\mathrm{r}=+0.286, \mathrm{p}<0.04)$

To evaluate the usefulness of the studied serum biomarkers for predicting liver fibrosis and cirrhosis at stage F3 and F4 according to METAVIR scoring system, the area under the ROC curve was analyzed. The area under the curve (AUC) of TGF- $\beta 1$ for identifying significant fibrosis (F3 and F4) was $0.716(\mathrm{p}<0.045)$, with a sensitivity $83.33 \%$ 
and specificity $75.0 \%$ at a cut off of 5.2. The PPV and NPV were 90.9 and 60.0 , respectively. The AUC of BMP-7 was 0.733 ( $\mathrm{p}<0.032$ ). The sensitivity was $84.6 \%$, and the specificity was $66.67 \%$ at a cut off 3.4 . PPV and NPV were 91.6 and 50.0, respectively (Figure 3). YKL-40 had an AUC of $0.896(\mathrm{p}<0.000)$ in diagnosing patients with HCC, with a sensitivity of $86.44 \%$ and a specificity $71.43 \%$ at a cut off of 2.06 . The PPV and NPV were 89.47 and 65.22, respectively (Figure 4).

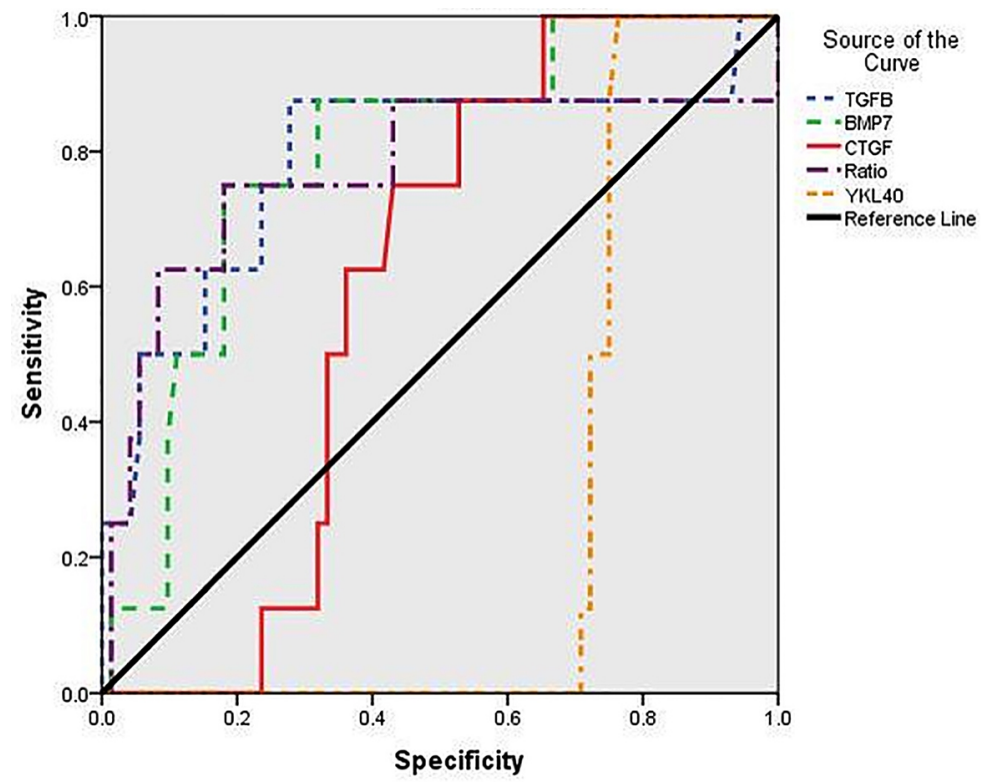

Figure 3. Receiver-operator characteristic (ROC) curves of serum biomarkers for prediction of significant fibrosis and cirrhosis (Metavir score F3 and F4). Data were analyzed considering patients with liver biopsy in the chronic hepatitis group. Among them TGF- $\beta 1$ and BMP-7 were the most sensitive and specific.

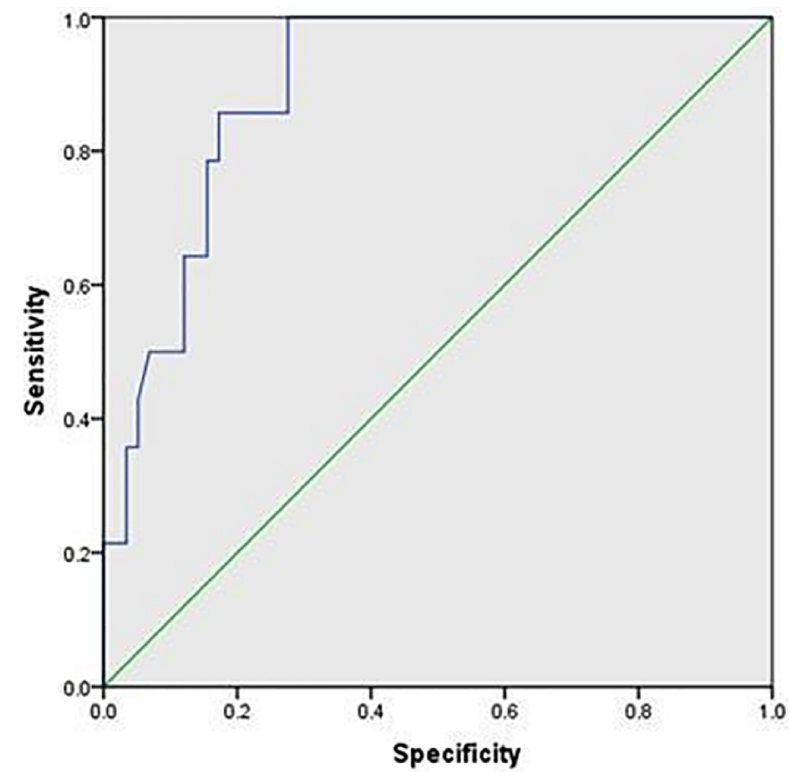

Figure 4. Receiver-operator characteristic (ROC) curve of YKL-40 for prediction of HCC

\section{Discussion}

Potentially powerful non-invasive (blood) biomarkers of hepatic fibrogenesis and fibrosis have been identified as our understanding of the pathogenesis of hepatic fibrosis has increased (8). Even though liver biopsy is an invasive technique that is subject to sampling error and significant intra- and inter-observer variability, it has been considered as the gold standard for determining the stages of liver fibrosis (17). When specific cells are lost in the course of a 
disease and are replaced by fibrotic tissue, type 2 EMT occurs in the parenchymal organs (liver, lungs, and kidneys) (18). The process by which cells gradually lose their typical epithelial characteristics and acquire mesenchymal traits is described by the epithelial-mesenchymal transition $(16,19)$. The epithelial-mesenchymal transition is governed by the balance of TGF- $\beta$ (pro-EMT) and its antagonist bone morphogenic protein-7 (BMP-7), i.e., anti-EMT (8). Both TGF- $\beta$ and BMP-7 share similar downstream Smad signalling pathways, but counter-regulate each other to maintain the balance of their biological activities (20). Bi et al. (21) stimulated primary rat liver epithelial cells with different ratios of TGF- $\beta 1 / \mathrm{BMP}-7$ and looked for any evidence of transition to a mesenchymal phenotype. This study showed that the contribution of the ratio of TGF- $\beta 1 / \mathrm{BMP}-7$ induced to EMT to the chronic liver diseases would provide a new basis for understanding pathogenesis and potential treatment. TGF- $\beta 1$ is a cytokine associated with hepatic fibrosis and is a homodimeric polypeptide that is secreted in an inactive form that requires activation. It is the most important stimulus for the production of ECM by HSCs (22). Additionally, TGF- $\beta 1$ can induce apoptosis in hepatocytes, hence, cirrhosis may be related to high levels of this cytokine in CHC patients (23).

In this study, the serum level of TGF- $\beta 1$ was found to be significantly higher in CHC, LC, and HCC patients than in the normal controls $(\mathrm{p}<0.001)$. Furthermore, the serum cytokine level increased gradually with increased stage of fibrosis to reach its highest level in liver cirrhosis $(p<0.001)$. These findings are supported by Neuman et al. (24) and Iagoda et al. (25), who stated that TGF- $\beta 1$ level reflected the histologic stage, and activation of latent TGF$\beta 1$ was reported to be the starting point of fibrogenesis. Luo et al. (26) reported a significant elevation of TGF- $\beta 1$ in liver cirrhosis, yet its correlation with the grade of activity was moderate. Some Egyptian studies $(22,27)$ conducted on chronic liver disease (CLD) due to $\mathrm{HCV}$ and other etiologic factors reported that TGF- $\beta 1$ was significantly increased in these patients compared to controls, with a high significant positive correlation between TGF- $\beta 1$ level and stage of liver fibrosis (28). An increasing number of reports have indicated that BMP-7 may be a new antagonist of fibrosis because of its counteractive effect on the TGF- $\beta 1 /$ Smad signaling pathway (29); however, only a few human studies have compared increased serum BMP-7 levels with the severity of hepatic fibrosis (30). Experimental studies have shown that a high serum BMP-7 level is an excellent indicator of the presence of fibrosis (31, 6). Recently, it became clear that some of the anti-fibrotic effects are mediated by the inhibition of pro-fibrogenic TGF$\beta 1$ (32), thus stopping ECM synthesis and the hepatocyte proliferation induced by TGF- $\beta$ (33, 34). In addition to its anti-EMT effect (14), BMP-7 was shown to have anti-apoptotic and anti-inflammatory activities. Thus, the measurement of BMP-7, alone or even in relation to TGF- $\beta$ in serum, which might reflect the velocity of fibrotic transition (35). In this study BMP-7, serum levels were elevated in patients with chronic liver disease, and they were significantly higher in patients with liver cirrhosis compared to CHC and HCC cases $(\mathrm{p}<0.001)$. Surprisingly, these results demonstrated elevations in BMP-7 levels with progression of fibrosis. This seems paradoxical considering the physiological role of BMP in the fibrosis process, which may be attributed to the compensatory increase of BMP-7 to counteract increased levels of TGF- $\beta 1$ and other profibrotic cytokines in patients with progressive liver disease. This is in agreement with Tacke et al. (35), who found elevated serum BMP-7 in patients with cirrhosis as compared to non-cirrhotic patients. Moreover, BMP-7 increased with the stage of fibrosis in accordance with Cao et al. (36) and Akdoğan et al. (37). Our results were in agreement with Gressner and Gao (38), who hypothesized that determination of the TGF- $\beta 1 /$ BMP-7 ratio in serum or plasma might reflect the process of EMT and, thus, at least partially, the rate of progression of fibrosis. The proteomic features of EMT include loss of epithelial markers, such as E-cadherin (E-cad), Zo-1, and cytokeratins, and the acquisition of fibroblast markers, including FSP-1,VM, matrix metalloproteinase (MMP)-2 and MMP-9, $\alpha$-smooth muscle actin ( $\alpha$-SMA), collagens, and TGF- $\beta 1$ (21). The results of this study indicated that the TGF- $\beta 1 / \mathrm{BMP}-7$ ratio was increased in liver fibrosis and HCC compared to normal controls. These results suggested that the TGF- $\beta 1 / \mathrm{BMP}-7$ ratio could be used to predict the intensity of hepatic fibrosis. This confirmed the results of other research in which it was proposed that the TGF- $\beta 1 / \mathrm{BMP}-7$ ratio could be used as a marker of disease severity in renal end points in patients with type 2 diabetes mellitus and lung fibrosis, respectively $(39,40)$. CTGF has been implicated in the pathogenesis of hepatic fibrosis and is currently suggested to be an important downstream amplifier of the effects of the pro-fibrogenic master cytokine TGF- $\beta 1$ (41) by modulation of the receptor binding of these ligands (42). Studies on circulating CTGF levels in assessment of hepatic fibrosis have just begun to gain momentum, and it was found that CTGF was over-expressed in fibrotic livers due to its production by multiple cell types, including HSC, hepa $\neg$ tocytes, portal fibroblasts, and cholangiocytes (43). After its expression, CTGF is secreted into the extracellular space and reaches the systemic circulation. Thus, serum CTGF could increase in patients with liver fibrosis (44). The spill-over of CTGF from the liver into the bloodstream indicates that this protein as an innovative, non-invasive, class I biomarker of fibrogenesis and indicates TGF- $\beta$ bioactivity in this organ (38). Indeed, CTGF-levels in sera correlated significantly with fibrogenic activity (6). The pathogenesis of hepatic fibrosis has been associated with connective tissue growth 
factor, and this factor currently is suggested to be an important downstream amplifier of the effects of TGF- $\beta 1$ (41). Its molecular mechanism of action is still not known, but it seems that this cytokine changes the functional TGF$\beta 1$ BMP-7 ratio (15). It activates TGF- $\beta$ signaling by modulation of the receptor binding of these ligands while inhibiting BMP (42). Recent investigations of patients with chronic hepatitis and cirrhosis have shown significantly elevated serum levels of CTGF, which could be well correlated with the progression of hepatic fibrosis $(43,44)$. In this study, the data clearly showed significant elevations of CTGF in the serum of patients with CHC, LC, and HCC compared to healthy individuals $(\mathrm{p}<0.001)$. CTGF concentration in LC was significantly higher than CHC ( $<<$ 0.01 ) but slightly decreased in HCC. These results also were in agreement with Weng et al. (46), Guo-Qiu et al. (47), Zhang et al. (44), Piao et al. (43), and Gressner et al. (48). CTGF acts as a mediator of fibre-fibre, fibre-matrix and matrix-matrix interactions and as an enhancer of profibrogenic TGF- $\beta 1$ with its several secondary effects. The increase of CTGF in the sera of HCC patients may be attributed to angiogenic, hypoxia-inducible, autocrine and paracrine factors that recruit myofibroblastic-like cells. Moreover, HSC/MFs, in addition to their established profibrogenic role, also may contribute to neo-angiogenesis during chronic hepatic wound healing (49). CTGF induces the expression of a variety of cytokines, such as TGF- $\beta$ (50) and VEGF (51), and may be up-regulated in HSC through endogenous TGF- $\beta 1$ (52). YKL-40, also known as human cartilage glycoprotein (39), is a secreted glycoprotein that belongs to a group of mammalian chitinase-like proteins, but it lacks chitinase activity (9). It is a growth factor for fibroblasts and endothelial cells and is expressed in areas of active hepatic fibrogenesis (53). It is derived from smooth muscle cells and also controls vessel stability and permeability via inducing association of $\mathrm{N}$ and VE-cad with $\beta$-catenin ( $\beta$-cate) expressed by smooth muscle cells and endothelial cells, respectively. In HCVinfected patients, the YKL-40 serum level is associated with the severity of HCV-induced fibrosis (54) and may be a useful non-invasive serum marker to estimate the degree of fibrosis $(55,56)$. Several studies (57-60) have indicated a role for YKL-40 in cancer cell proliferation and invasiveness. In the current work, serum YKL40 was higher in all studied patients compared to healthy controls. Its level in cirrhotic patients was significantly higher compared to CHC cases $(\mathrm{p}<0.01)$. These results are in agreement with other studies $(9,53,54,61)$. Rath et al. (62) suggested that YKL-40 was a powerful fibrosis marker with high diagnostic accuracy, particularly in HCV-associated liver disease. Moreover, our results revealed that the greatest significant increase was detected in HCC patients, which was consistent with Zhu et al. (63). Pelloski et al. (64) suggested that serum levels of YKL-40 serve as a diagnostic and prognostic cancer biomarker. YKL-40 is expressed by both tumor cells and their surrounding tumor infiltrating macrophages that produce various tumor-promoting factors, including vascular endothelial growth factor (VEGF), epidermal growth factor (EGF), basic fibroblastic growth factor (bFGF), and platelet-derived growth factor (PDGF) (65). Current results have reported that YKL-40 in HCC patients was significantly higher than in cirrhotic patients $(p<0.05)$. On the contrary, Xiao et al. (9) did not detect a significant difference between these two groups.

\section{Conclusions}

It was concluded that the increase of TGF- $\beta 1 / \mathrm{BMP}-7$ ratio may reflect the rate of EMT in HCV hepatic patientsgenotype 4. The simultaneous determination of TGF- $\beta / B M P-7$ ratio and of CTGF in serum might provide information on fibrogenic activity, while this ratio in association with YKL-40 can be used for prediction of the malignant transformation.

\section{Acknowledgments:}

We are grateful to the Theodor Bilharz Research Institute, internal project No. 86 sh. This work was conducted in and financed by the Institute.

\section{Conflict of Interest:}

There is no conflict of interest to be declared.

\section{Authors' contributions:}

All authors contributed to this project and article equally. All authors read and approved the final manuscript.

\section{References}

1) Mahmoud YA, Mumtaz GR, Riome S, Miller D, Abu-Raddad LJ. The epidemiology of hepatitis $C$ virus in Egypt: a systematic review and data synthesis. BMC Infect Dis. 2013; 13: 288. doi: 10.1186/1471-2334-13288, PMID: 23799878 , PMCID: PMC3702438.

2) Ahram Online. Fact box: 15 facts about Hepatitis $C$ in Egypt and the latest approved drugs. 15th Annual Congress of the Egyptian Society of Hepatology, Gastroenterology and Infectious Diseases. Ahram Online 
used the recommendations of the panel, along with information from the Egyptian Ministry of Health and World Health Organization (WHO) Ingy Deif, Cairo, Thursday 29 May 2014.

3) Averhoff FM, Glass N, Holtzman D. Global burden of Hepatitis C: Considerations for healthcare providers in the United States. Clin Infect Dis. 2012; 55(1): 10-15. doi: 10.1093/cid/cis361, PMID: 22715208.

4) Andrade LJO, Junior AD, Melo RC, De Souza EC, Silva CAC, Paraná R. Association between Hepatitis $\mathrm{C}$ and Hepatocellular Carcinoma. J Glob Infect Dis. 2009; 1(1):33-7. doi: 10.4103/0974-777X.52979, PMID: 20300384 , PMCID: PMC2840947.

5) Gressner OA, Rizk MS, Kovalenko E, Weiskirchen R, Gressner AM. Changing the pathogenetic roadmap of liver fibrosis? Where did it start; where will it go? J Gastroenterol Hepathol. 2008; 23:1024-35. doi: 10.1111/j.1440-1746.2008.05345.x , PMID: 18505415.

6) Gressner OA, Gressner AM . Connective tissue growth factor: a fibrogenic master switch in fibrotic liver diseases. Liver Int. 2008; 28: 1065-79. doi: 10.1111/j.1478-3231.2008.01826.x, PMID: 18783549

7) Johansen JS. Studies on serum YKL-40 as a biomarker in diseases with inflammation, tissue remodeling, fibroses and cancer. Dan Med Bull. 2006; 53:172-209. PMID: 17087877.

8) Gressner AM, Gao CF, Gressner OA. Non-invasive biomarkers for monitoring the fibrogenic process in liver: a short survey. World J Gastroenterol. 2009; 15: 2433-2440. doi: 10.3748/wjg.15.2433, PMID: 19468990 , PMCID: PMC2686898

9) Xiao XQ, Hassanein T, Li QF, Liu W, Zheng YH, Chen J. YKL-40 expression in human hepatocellular carcinoma: a potential biomarker? Hepatobiliary Pancreat Dis Int. 2011; 10: 605-10. doi: 10.1016/S14993872(11)60103-3.

10) Gressner AM, Yagmur E, Lahme B, Gressner O, Stanzel S. Connective tissue growth factor in serum as a new candidate test for assessment of hepatic fibrosis. Clin Chem. 2006; 52: 1815-17. doi: 10.1373/clinchem.2006.070466, PMID: 16858074.

11) Friedman SL. Mechanisms of hepatic fibrogenesis, Gastroenterology. 2008; 134(6): 1655-69. doi: 10.1053/j.gastro.2008.03.003, PMID: 18471545 , PMCID: PMC2888539.

12) Pegorier S, Campbell GA, Kay AB, Lloyd CM. Bone morphogenetic protein (BMP)-4 and BMP-7 regulate differentially transforming growth factor (TGF)-betal in normal human lung fibroblasts (NHLF). Respir Res. 2010; 11: 85. doi: 10.1186/1465-9921-11-85, PMID: 20573231, PMCID: PMC2898775

13) Rachfal AW, Brigstock DR. Connective tissue growth factor (CTGF/CCN2) in hepatic fibrosis. Hepatol Res. 2003; 26:1-9. doi: 10.1016/S1386-6346(03)00115-3

14) Gressner O, Weiskirchen R, Gressener AM. Evolving concepts of liver fibrogenesis provide new diagnostic and therapeutic options. Comp Hepatol. 2007; 6:7-20. doi: 10.1186/1476-5926-6-7, PMID: :17663771, PMCID: PMC1994681.

15) Abreu JG, Ketpura NI, Reversade B, De Robertis EM. Connective-tissue growth factor (CTGF) modulates cell signaling by BMP and TGF-beta. Nat Cell Biol. 2002; 4:599-604, PMID: 12134160, PMCID: PMC2387275.

16) Choi SS, Diehl AM. Epithelial-to-mesenchymal transitions in the liver. Hepatology 2009; 50:2007-13. doi: 10.1002/hep.23196, PMID: 19824076, PMCID: PMC2787916.

17) Schiavon LL, Narciso-Schiavon JL and de Carvalho-Filho RJ: Noninvasive diagnosis of liver fibrosis in chronic hepatitis C. World J Gastroenterol. 2014; 20: 2854-66. doi: 10.3748/wjg.v20.i11.2854, PMID: 24659877 , PMCID: PMC3961992.

18) Thiery JP, Acloque H, Huang RY. Epithelial mesenchymal transitions in development and disease. Cell. 2009; 139: 871-90. doi: 10.1016/j.cell.2009.11.007, PMID: 19945376.

19) Soto-Gutierrez A, Navarro-Alvarez N, Kobayashi N. Molecular pathology of liver diseases: Hepatocytes. Molecular Pathology Library. 2010; 5:17-26. doi: 10.1007/978-1-4419-7107-4_3.

20) Meng XM, Chung ACK, Lan HY. Role of the TGF- $\beta / B M P-7 /$ Smad pathways in renal diseases. Clin Sci. 2013; 124: 243-54. doi: 10.1042/CS20120252, PMID: 23126427.

21) W.R. Bi1, G.T. Xu2, L.X. Lv2, C.Q. Yang. The ratio of transforming growth factor- $\beta 1 /$ Bone morphogenetic protein-7 in the progression of the epithelial mesenchymal transition contributes to rat liver fibrosis. Genet. Mol Res. 2014; 13(1): 1005-14. doi: 10.4238/2014.February.20.2

22) Nassef YE, Shady MM, Galal EM, Hamed MA. Performance of diagnostic biomarkers in predicting liver fibrosis among hepatitis C virus-infected Egyptian children. Mem Inst Oswaldo Cruz. 2013; 108: 887-93. doi: 10.1590/0074-0276130139, PMID: 24141960, PMCID: PMC3970648. 
23) Divella R, Daniele A, Gadaleta $C$, et al. Circulating transforming growth factor- $\beta$ and epidermal growth factor receptor as related to virus infection in liver carcinogenesis. Anticancer Res. 2012; 32:141-45, PMID: 22213299.

24) Neuman MG1, Benhamou JP, Bourliere M, Ibrahim A, Malkiewicz I, Asselah T et al. Serum tumor necrosis factor-alpha and transforming growth factor-beta levels in chronic hepatitis $\mathrm{C}$ patients are immunomodulated by therapy. Cytokine. 2002; 17: 108-17. doi: 10.1006/cyto.2001.0997, PMID: 11886178.

25) Iagoda AB, Koror PV, Geǐvandova NI, Nikitina OA, Kastornaia IV. Growth factors and the hystologic picture of the liver in chronic viral hepatitis and hepatic cirrhosis. Klin Med (Mosk). 2006; 84(4): 44-7.

26) Luo R, Yang S, Xie J, Zhao Z, He Y, Yao J. Diagnostic value of five serum markers for liver fibrosis. Zhonghua Gan Zang Bing Za Zhi. 2001; 9: 148-150, PMID: 11412388.

27) Abdel-Ghaffar TY, Behairy BE, El-Shaheed A, Tawhida Y, Karam Mahdy, Mohamed El et al. Clinical benefits of biochemical markers of fibrosis in Egyptian children with chronic liver diseases. Gastroenterol Res. 2010; 3:262-71. doi: 10.4021/gr246w.

28) Nawar EA, Abul-fadl AM, Hassanin BE, Abd El Haie OM, EL-Tokhy M. Clinical value of transforming growth factor beta as a marker of fibrosis in adolescents with chronic liver diseases. J American Science. 2011; 7(3): 464-71.

29) Chen BL, Peng J, Li QF, Yang M, Wang Y, Chen W. Exogenous bone morphogenetic protein-7 reduces hepatic fibrosis in Schistosoma japonicum-infected mice via transforming growth factor- $\beta /$ Smad signaling. World J Gastroenterol. 2013; 19:1405-15. doi: 10.3748/wjg.v19.i9.1405, PMID: 23539268, PMCID: PMC3602500.

30) Demir N1, Kolgelier S, Inkaya AC, Sumer S, Demir LS, Pehlivan FS, et al. Are bone morphogenetic protein-7 (BMP-7) serum levels correlated with development of hepatic fibrosis? J Infect Dev Ctries. 2014; 8(5):605-10, PMID: 24820464.

31) Sakamoto N, Yoshimura M, Kimura $T$, Toyama K, Sekine-Osajima $Y$, Watanabe $M$, et al. Bone morphogenetic protein-7 and interferon-alpha synergistically suppress hepatitis $\mathrm{C}$ virus replicon. Biochem Biophys Res Commun. 2007; 357(2): 467-73. doi: 10.1016/j.bbrc.2007.03.167, PMID: 17433261.

32) Weiskirchen R, Meurer SK, Gressner OA, Herrmann J, Borkham-Kamphorst E, Gressner AM. BMP-7 as antagonist of organ fibrosis. Front Biosci (Landmark Ed). 2009; 14: 4992-5012. doi: 10.2741/3583, PMID: 19482601.

33) Zeisberg M, Hanai J, Sugimoto H, Mammoto T, Charytan D, Strutz F, et al. BMP-7 counteracts TGFbeta1-induced epithelial-to-mesenchymal transition and reverses chronic renal injury. Nat Med. 2003; 9(7): 964-8. doi: 10.1038/nm888, PMID: 12808448.

34) Kinoshita K1, Iimuro Y, Otogawa K, Saika S, Inagaki Y, Nakajima Y, et al. Adenovirus-mediated expression of BMP-7 suppresses the development of liver fibrosis in rats. Gut. 2007; 56(5): 706-14. doi: 10.1136/gut.2006.092460, PMID: 17127702, PMCID: PMC1942155.

35) Tacke F, Gäbele E, Bataille F, Robert F. Schwabe, Hellerbran C, et al. Bone morphogenetic protein 7 is elevated in patients with chronic liver disease and exerts fibrogenic effects on human hepatic stellate cells. Dig Dis Sci. 2007; 52(12): 3404-15. doi: 10.1007/s10620-007-9758-8, PMID: 17415633.

36) Cao H, Shu X, Chen LB, Zhang K, Xu QH, Li G. The relationship of expression of BMP-7 in the liver and hepatic inflammation and fibrosis in patients with chronic HBV infection. Zhonghua Shi Yan He Lin Chuang Bing Du Xue Za Zhi. 2010; 24(2): 101-3, PMID: 21110425.

37) Akdoğan MF, Azak A, Huddam B, Sakaci M, Kocak G, Denizli N, et al. Influence of bone morphogenic protein 7 (bmp7) on the progression of chronic kidney disease. J Nephrol Urol Res. 2014; 2(1): 1-8. doi: 10.12970/2310-984X.2014.02.01.1.

38) Gressner OA, Gao C. Monitoring fibrogenic progression in the liver. Clin Chim Acta. 2014; 433: 111-22. doi: 10.1016/j.cca.2014.02.021, PMID: 24607331.

39) Wong MG, Perkovic V, Woodward M, Chalmers J, Li Q, Hillis GS et al. Circulating bone morphogenetic protein-7 and transforming growth factor- $\beta 1$ are better predictors of renal end points in patients with type 2 diabetes mellitus. Kidney Int, 2013;83: 278-84. doi: 10.1038/ki.2012.383, PMID: 23235570

40) Stumm CL, Halcsik E, Landgraf RG, Camara NO, Sogayar MC, Jancar S. Lung remodeling in a mouse model of asthma involves a balance between TGF- $\beta 1$ and BMP-7. PLoS One, 2014; 9(4): e95959. doi: 10.1371/journal.pone.0095959, PMID: 24781156, PMCID: PMC4004563.

41) Leask A, Abraham DJ. All in the CCN family: essential matricellular signaling modulators emerge from the bunker. J Cell Sci. 2006; 119: 4803-10. doi: 10.1242/jcs.03270, PMID: 17130294. 
42) Jou J, Diehl AM. Epithelial-mesenchymal transitions and hepatocarcinogenesis. J Clin Invest. 2010; 120: 1031-4. doi: 10.1172/JCI42615, PMID: 20335655, PMCID: PMC2846072.

43) Piao RL, Brigstock DR, Zhu J, Zhang ML, Gao RP. Clinical significance of connective tissue growth factor in hepatitis B virus-induced hepatic fibrosis. World J Gastroenterol. 2012; 18: 2280-6. doi: 10.3748/wjg.v18.i18.2280, PMID: 22611323, PMCID: PMC3351780.

44) Zhang DY, Friedman SL. Fibrosis-dependent mechanisms of hepatocarcinogenesis. Hepatology, 2012; 56: 769-75. doi: 10.1002/hep.25670, PMID: 22378017 , PMCID: PMC4087159.

45) Dendooven A, Gerritsen KG, Nguyen TQ, Kok RJ, Goldschmeding R. Connective tissue growth factor (CTGF/CCN2) ELISA: a novel tool for monitoring fibrosis. Biomarkers. 2011; 16: 289-301. doi: 10.3109/1354750X.2011.561366, PMID: 21595567.

46) Weng HL, Ciuclan L, Liu Y, Hamzavi J, Godoy P, Gaitantzi H, et al. Profibrogenic transforming growth factor-beta/activin receptor-like kinase 5 signaling via connective tissue growth factor expression in hepatocytes. Hepatology. 2007; 46: 1257-70. doi: 10.1002/hep.21806, PMID: 17657819.

47) Guo-Qiu W, Nai-Feng L, Xiao-Bo V, Linxian L, Chen Z, Lixia G, et al. The level of connective tissue growth factor in sera of patients with hepatitis B virus strongly correlates with stage of hepatic fibrosis. Viral Immunol. 2010; 23: 71-8. doi: 10.1089/vim.2009.0067, PMID: 20121404.

48) Gressner OA, Fang M, Li H, Lu LG, Gressner AM, Gao CF. Connective tissue growth factor $(\mathrm{CTGF} / \mathrm{CCN} 2)$ in serum is an indicator of fibrogenic progression and malignant transformation in patients with chronic hepatitis B infection. Clin Chim Acta. 2013; 421: 126-31. doi: 10.1016/j.cca.2013.02.029, PMID: 23501329.

49) Novo E, Cannito S, Zamara E, Valfrè di Bonzo L, Caligiuri A, Cravanzola C, et al. Proangiogenic cytokines as hypoxia-dependent factors stimulating migration of human hepatic stellate cells. Am J Pathol. 2007; 170: 1942-53. doi: 10.2353/ajpath.2007.060887, PMID: 17525262, PMCID: PMC1899450.

50) Yang H, Huang Y, Chen X, Liu J, Lu Y, Bu L, et al. The role of CTGF in the diabetic rat retina and its relationship with VEGF and TGF- $\beta(2)$, elucidated by treatment with CTGF siRNA. Acta Ophthalmol. 2010; 88: 652-9. doi: 10.1111/j.1755-3768.2009.01641.x, PMID: 20039857.

51) Liu FY, Xiao L, Peng YM, Duan SB, Liu H, Liu YH, et al. Inhibition effect of small interfering RNA of connective tissue growth factor on the expression of vascular endothelial growth factor and connective tissue growth factor in cultured human peritoneal mesothelial cells. Chin Med J. 2007; 120: 231-6. PMID: 17355828.

52) El-Bassiouni NE, Nosseir MM, Madkour ME, Zoheiry MM, Bekheit IW, Ibrahim RA, et al. Role of fibrogenic markers in chronic hepatitis $\mathrm{C}$ and associated hepatocellular carcinoma. Mol Biol Rep. 2012; 39: 6843-50. doi: 10.1007/s11033-012-1509-z, PMID: 22318548.

53) Fontana RJ, Dienstag JL, Bonkovsky HL, Sterling RK, Naishadham D, Goodman ZD, et al. Serum fibrosis markers are associated with liver disease progression in non-responder patients with chronic hepatitis $\mathrm{C}$. Gut. 2010; 59: 1401-9. doi: 10.1136/gut.2010.207423, PMID: 20675691, PMCID: PMC3740000.

54) Berres ML, Papen S, Pauels K, Schmitz P, Zaldivar MM, Hellerbrand C, et al. A functional variation in CHI3L1 is associated with severity of liver fibrosis and YKL-40 serum levels in chronic hepatitis C infection. J Hepatol. 2009; 50: 370-6. doi: 10.1016/j.jhep.2008.09.016, PMID: 19070929.

55) Saitou Y, Shiraki K, Yamanaka Y, Yamaguchi Y, Kawakita T, Yamamoto N, et al. Noninvasive estimation of liver fibrosis and response to interferon therapy by a serum fibrogenesis marker, YKL-40, in patients with HCV-associated liver disease. World J Gastroenterol. 2005; 11: 476-81. doi: 10.3748/wjg.v11.i4.476. , PMID: 15641129, PMCID: PMC4250794.

56) Pungpapong S, Nunes DP, Krishna M, Nakhleh R, Chambers K, Ghabril M, et al. Serum fibrosis markers can predict rapid fibrosis progression after liver transplantation for hepatitis C. Liver Transpl. 2008; 14: 1294-302. doi: 10.1002/lt.21508, PMID: 18756457.

57) Johansen JS, Schultz NA, Jensen BV. Plasma YKL-40 a potential new cancer biomarker? Future Oncol. 2009; 5: 1065-82. doi: 10.2217/fon.09.66, PMID: 19792974.

58) Horbinski C, Wang G, Wiley CA. YKL-40 is directly produced by tumor cells and is inversely linked to EGFR in glioblastomas. Int J Clin Exp Pathol. 2010; 3:226-237, PMID: 20224722, PMCID: PMC2836500

59) Malaguarnera G, Giordano M, Paladina I, Berretta M, Cappellani A, Malaguarnera M. Serum markers of hepatocellular carcinoma. Dig Dis Sci. 2010; 55: 2744-55. doi: 10.1007/s10620-010-1184-7, PMID: 20339916.

60) Thöm I, Andritzky B, Schuch G, Burkholder I, Edler L, Johansen JS, et al. Elevated pretreatment serum concentration of YKL-40-An independent prognostic biomarker for poor survival in patients with 
metastatic non-small cell lung cancer. Cancer. 2010; 116: 4114-421. doi: 10.1002/cncr.25196, PMID: 20564116.

61) Pizano-Martinez O, Yañez-Sánchez I, Alatorre-Carranza P, Miranda-Díaz A, Ortiz-Lazareno PC, GarcíaIglesias $\mathrm{T}$, et al. YKL-40 expression in CD14+ liver cells in acute and chronic injury. World J Gastroenterol. 2011; 17: 3830-5. doi: 10.3748/wjg.v17.i33.3830, PMID: 21987626, PMCID: PMC3181445.

62) Rath T, Roderfeld M, Güler C, Wenzel C, Graf J, Beitinger F, et al. YKL-40 and transient elastography, a powerful team to assess hepatic fibrosis. Scand J Gastroenterol. 2011; 46: 1369-80. doi: 10.3109/00365521.2011.613949, PMID: 21905976.

63) Zhu CB, Wang C, Chen LL, Ma GL, Zhang SC, Su L, et al. Serum YKL-40 independently predicts outcome after transcatheter arterial chemoembolization of hepatocellular carcinoma. PLoS One. 2012; 7(9): e44648. doi: 10.1371/journal.pone.0044648, PMID: 22970277, PMCID: PMC3435289.

64) Pelloski CE, Mahajan A, Maor M, Chang EL, Woo S, Gilbert M, et al. YKL-40 expression is associated with poorer response to radiation and shorter overall survival in glioblastoma. Clin Cancer Res. 2005; 11:3326-3334. doi: 10.1158/1078-0432.CCR-04-1765, PMID: 15867231.

65) Ganapathy V, Ge R, Grazioli A, Xie W, Banach-Petrosky W, Kang Y, et al. Targeting the transforming growth factor-beta pathway inhibits human basal-like breast cancer metastasis. Mol Cancer. 2010; 9: 122. doi: 10.1186/1476-4598-9-122, PMID: 20504320, PMCID: PMC2890606. 